\title{
In-Flight Evaluation of Pure Time Delays in Pitch and Roll
}

Donald T. Berry

August 1985
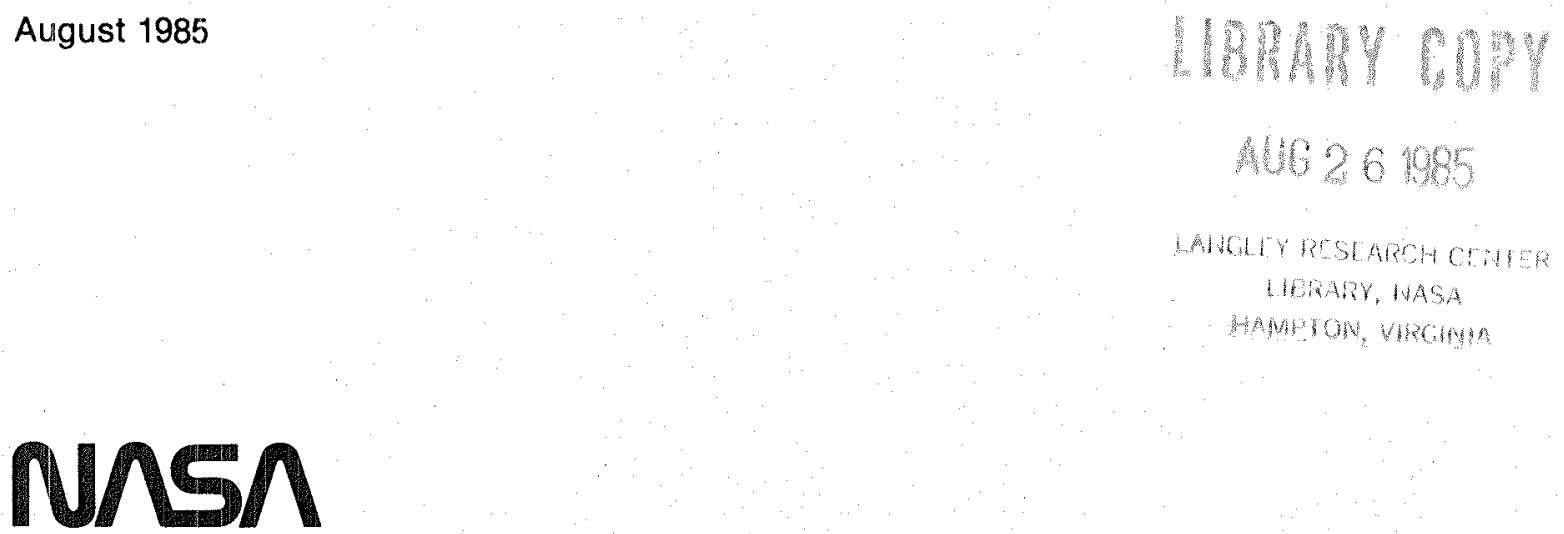

National Aeronautics and

Space Administration 
31176001912980 
NASA Technical Memorandum 86744

\section{In-Flight Evaluation of Pure Time Delays in Pitch and Roll}

Donald T. Berry

Ames Research Center, Dryden Flight Research Facility, Edwards, California

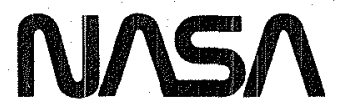

National Aeronautics and

Space Administration

Ames Research Center

Dryden Flight Research Facility

Edwards, California 93523

$185-3,173$ 
IN-FLIGHT EVALUATION OF PURE TIME DELAYS IN PITCH AND ROLL

\author{
Donald T. Berry* \\ NASA Ames Reserch Center \\ Dryden Flight Research Facility \\ Edwards, California
}

Abstract

An in-flight investigation of the effect of pure time delays in pitch and roll was undertaken. The evaluation tasks consisted of low lift-to-dragratio landings of various levels of difficulty and formation flying. The results indicate that the effect of time delay is strongly dependent on the task. In the pitch axis, in calm air, spot landings from a lateral offset were most strongly influenced by time delay. In the roll axis, in calm air, formation flying was most strongly influenced by time delay. However, when landings were made in turbulence, flying qualities in pitch were only slightly degraded, whereas in roll they were severely degraded.

\section{Nomenclature}

AGL above ground level

above sea level

ay lateral acceleration, $g$

$C_{L}$

$C_{\ell}$

$C_{m}$

$C_{n}$

$c_{y}$

$\vec{c}$

DFBW

$I_{X}$

Iy pitch inertia, ft-1b-sec 2

$I_{z} \quad$ yaw inertia, ft-1b-sec ${ }^{2}$

KIAS indicated airspeed, knots

KLA lateral-directional aileron gain

$K_{p} \quad$ roll rate feedback gain

$\mathrm{K}_{\mathrm{q}} \quad$ pitch rate feedback gain

$k_{r} \quad$ yaw rate feedback gain

\section{$L / D$ \\ Tift-to-drag ratio}

PIO

PR

$\mathrm{p}$

q

$\vec{q}$

$r$

SAS

s.

$\alpha$

$\dot{\alpha}$

B

$\dot{\beta}$

$\delta_{\mathrm{a}}$

$\delta_{\mathrm{e}}$

$\delta_{r}$

Y

$\Delta$

Subscripts $p, q, r, \alpha, \beta, \dot{\alpha}, \dot{\beta}, \quad$ nondimensional stability deriva-
$\delta_{a}, \delta_{e}, \delta_{r}$ tives with respect to indicated quantity

\section{Introduction}

In the late 1970's and early 1980's overcontrol and pilot-induced oscillation (PIO) tendencies were observed during flight tests of some of the new advanced technology vehicles, such as the space shuttle and the F-16.1 Assessments indicated that time delays associated with higher-order systems and digital flight control were a contributing factor. Consequently, a flight test program was conducted on the Ames-Dryden F-8 digital fly-by-wire (DFBW) aircraft to expand the data base on this subject.2 The emphasis in this program was on pitch control in low lift-to-drag-ratio (L/D) landings such as those performed with the space shuttle. However, roll control data were also

*Aerospace Engineer, Flight Operations and Research Division, Associate Fellow, AIAA. 
taken although not reported in Ref. 2. Since that time problems with time delay persist, and additional questions have arisen with regard to roll time delay in more recent advanced aerospace vehicles such as the $F-18, A F T I / F-16$, and $X-29$. This paper analyzes and reports the data for roll time delays obtained with the F-8 DFBW airplane, and compares them with the pitch results of Ref. 2 .

\section{Description of Aircraft and Flight Control System}

The F-8 digital fly-by-wire (DFBW) aircraft is a modified $F-8 C$ single-engine, single-place Navy fighter (Fig. 1). The aircraft has a two-position wing for reducing fuselage attitude during landing approach. The $F-8 C$ was modified by removing the entire mechanical control system between the stick and rudder pedals and the actuators, and replacing it with a digital fly-by-wire control system implemented with onboard digital computers.

The F-8 DFBW aircraft includes several control law functions for use in active control applications that are pilot selectable. In this paper, only the stability augmentation system (SAS) modes are pertinent. The SAS pitch mode uses washed-out pitch rate feedback to improve short period damping (Fig. 2). Figure 3 illustrates the lateraldirectional SAS modes. (The pilot's rudder input channel is not shown because the pilots did not use rudder in the experiment.) Although the roll and yaw SAS modes are individually selectable by the pilot, they are discussed collectively. This system provides improved dutch roll damping and directional stability as well as turn coordination. High-passed yaw rate provides increased dutch roll damping with minimal steady-state effect. Turn coordination is provided by a compensated aileronto-rudder interconnect that utilizes a first-order lagged signal. Turn coordination is also enhanced by feeding back roll rate to the rudder.

All filtering and control law computation, illustrated in Figs. 2 and 3, is performed in the digital computer. The digital computation and processing introduces pure time (transport) delays into the control system. In addition, higher-order effects and nonlinearities in the actuators introduce additional apparent transport delays. A typical value for the effective transport delays inherent in the F-8 DFBW control system and a summary of aircraft and flight control system characteristics are presented in Tables 1 and 2. The aircraft and systems are described in detail in Ref. 3.

\section{Flight Test Procedures}

Four basic tasks were evaluated during the flight program: normal low-L/D landings, low-L/D spot landings, low $L / D$ spot landings from a lateral offset, and formation flying. The formation flying was done to see if an up-and-away evaluation task could provide insight into the control problems that would occur on an actual landing.

During the low-L/D approaches, the engine was at idle power and the landing gear and wings were down. Approaches were initiated at 260 KIAS, $7000 \mathrm{ft}$ above sea level ( $4800 \mathrm{ft}$ above ground level), about $6 \mathrm{mi}$ from touchdown point. A speed of 260 KIAS was ma intained to $500 \mathrm{ft}$ above ground level. The outer glide slope was approximately $10^{\circ}$. Flare was initiated $500 \mathrm{ft}$ above ground level. A glide slope of approximately $1^{\circ}$ was intercepted about $100 \mathrm{ft}$ above ground level. Aim touchdown speed was 190 KIAS; actual touchdown speeds were between 180 and 210 KIAS. Outer glide slope aim point was about $1 \mathrm{mi}$ from the runway threshold.

All landings were made on a concrete runway $15,000 \mathrm{ft}$ long and $300 \mathrm{ft}$ wide. The evaluation terminated at touchdown, and a go-around was initiated. The normal $10 w-L / D$ landings were made from straight-in approaches with no particular aim touchdown point. Owing to the generous proportions of the runway, these were relatively unstressed landings. The low-L/D spot landings were made from straight-in approaches, but the pilot was asked to touch down at the $5000-\mathrm{ft}$ marker on the runway. The low-L/D spot landings from the lateral of fset consisted of an approach lined up with the edge of the runway, followed by an offset maneuver (initiated at $100 \mathrm{ft}$ above ground level, approximately $1 \mathrm{mi}$ to touchdown) to line up with the runway centerline, and a touchdown at the 5000-ft marker. The lateral offset increased the pilot's workload and stress, providing a more demanding landing task. A representative flight profile for these landings is shown in Fig. 4 .

The formation flying task simulated an aerial refueling positioning. The aircraft was initially stabilized 25 to $50 \mathrm{ft}$ below another aircraft at various horizontal distances: $100 \mathrm{ft}$ the farthest, $10 \mathrm{ft}$ the closest. Abrupt pitch inputs positioned the F-8 approximately $10 \mathrm{ft}$ below the "tanker" (Fig. 5), in the refueling position. Roll evaluation maneuvers for the simulated refueling formation task consisted of rapid, lateral control inputs to move quickly, either from the refueling position to a wingtip position, or from a position two to three wingspans abeam of the refueling position to the refueling position. After obtaining the final position, an attempt was made to maintain it precisely.

The digital computer was programmed to provide pilot-selectable incremental time delay values of $20,60,100,140$, and $200 \mathrm{msec}$ independently in pitch and roll. These increments were added in the pilot input path ahead of the control system feedback summing junction (Figs. 2 and 3 ); consequently, the lags within the closed-loop portion of the system were unaffected. In addition to these incremental time delays, the aircraft has an inherent pure time delay between pilot stick input and pitch control surface movement of approximately $130 \mathrm{msec}$.

The study consisted of 16 flights and 170 evaluations, with four pilots participating. There was one approach or formation flying task for each evaluation. Six flights were primarily pilot checkout and indoctrination flights in which the pilots familiarized themselves with the various configurations, explored various tasks, and conducted preliminary evaluations. On subsequent flights the pilots formally evaluated the various tasks for different time delays, and provided comments and ratings. The Cooper-Harper rating scale was used. ${ }^{4}$

Because of time and equipment constraints, the pilot was aware of the configuration he was selecting. In addition, in most cases, configurations 
were evaluated in order, starting with zero time delay and increasing to maximum. This introduced the possibility of reduced pilot objectivity. However, it is believed that a high degree of objectivity did exist because (1) all pilots were highly experienced test pilots who had displayed a great degree of objectivity and consistency over the years; (2) none of the pilots knew the ratings assigned by other pilots in the program; and (3) configurations were arbitrarily selected for repeat evaluations. This is confirmed by the good agreement in the ratings between the pilots and for repeated configurations with the same pilot.

Most of the evaluations were performed in air with light turbulence or less. Data acquired in. greater turbulence are so identified.

\section{Results of Pilot Rating Trends}

Figures 6(a) through (d) present pilot ratings in roll as a function of incremental time delay for the low-L/D landing tasks and formation flying. The lines are a least-squares, straightline fit to the data. In most cases the scatter in the data is low and the data are well represented by the straight lines.

Figure 6 (a) contains data for normal, relatively unstressed, $10 w-L / D$ landings. It is the only case for which data with turbulence is available and the influence is quite evident. Figure $6(b)$ presents data for $10 w-L / D$ spot landings. Figure $6(\mathrm{C})$ provides data for $10 \mathrm{w}-L / D$ offset spot landings. Figure $6(d)$ provides data for the formation flying task. The pilot ratings degrade with increasing transport delay as the task goes from normal landings, to spot landings, to off set spot landings, and finally, to formation flying. However, turbulence produces the greatest degradation (Fig. 6(a).

PI0s occurred during the more demanding lateral tasks (such as formation flying and landing in turbulence with side gusts) and during the tasks having the larger time delays. Figure 7 illustrates a PIO that occurred during landing approach with an incremental time delay of $60 \mathrm{msec}$. The pilot commented that he had a good crosswind gust near the ground which drove his gains up and resulted in a "pretty good roll PIO." This resulted in a pilot rating of 6 . Figure 8 illustrates an example of PIO during formation flying. The incremental time delay was $140 \mathrm{msec}$, and the pilot rated this configuration a 7 . Pilot comments indicate that the PIO could only be avoided by abandoning the formation flying task.

Figure 9 illustrates the sensitivity of pilot ratings to changes in time delay. (The sensitivities are the slopes of the least-squares, straight-line fit of pilot rating as a function of incremental time delay.) In calm air, normal landings were the least sensitive and formation flying the most sensitive. Spot landings were similar to normal landings, and offset spot landings were intermediate in sensitivity. Pilot rating sensitivity to time delay is an indication of task difficulty or stress. The lateral task for a spot landing is not much different than a normal

landing. The offset spot landing and formation flying, however, have definite lateral tasks, and the data trends are consistent with this. The data show, however, that turbulence is a strong factor. Pilot comments indicate that the turbulence in these tests included side gusts that moved the aircraft off the runway centerline, adding significantly to the lateral task. Consequently, the pilot rating sensitivity to time delay was very high.

Figure 10 compares these results with data from Ref. 2 on the sensitivity of pilot rating to time delay for longitudinal tasks. It can be seen that longitudinal ratings from normal landings are least sensitive and offset spot landings are most sensitive. Offset spot landings do complicate the longitudinal task. The longitudinal task in formation flying, however, is apparently less demanding. of particular interest, is that turbulence had considerably less influence on the longitudinal ratings than on the lateral ratings. This could be the result of the turbulence environment or the gust sensitivities of the aircraft.

If the low pilot rating sensitivities are associated with low stress situations, and the high pilot rating sensitivities are associated with high stress, the results of this study can be summarized in Fig. 11. Similar data from Ref. 2 for the longitudinal pilot ratings are also presented. The low stress level results are less severe for the lateral tasks, but that high stress level results appear to be more severe for the lateral tasks. Apparently this is caused by the greater sensitivity of the lateral results to turbulence. Unfortunately, it was not possible to document in a quantitative fashion the nature of the turbulence experienced in this program. However, these results do indicate the importance of examining the gust sensitivity of configurations when considering the influence of time delays.

By adding the inherent time delay in the F-8 DFBW airplane to the incremental time delays, the results can also be summarized in terms of total time delay and be compared to the Military Specification requirements (Ref. 5), as was done in Ref. 6. This summary is presented in Fig. 12. If it is assumed that the Military Specification requirements represent high-stress conditions, then the requirements may be too stringent for longitudinal time delay, but quite reasonable for lateral time delays.

\section{Concluding Remarks}

The effect of pure time delays in pitch and roll was investigated in flight. The evaluation tasks consisted of low lift-to-drag-ratio landings of various levels of difficulty and formation flying. The results indicate that the effect of time delay strongly depends on the task. In the pitch axis, in calm air, spot landings from a lateral offset were most strongly influenced by time delay. In the roll axis, in calmair, formation flying was most strongly influenced by time delay. However, when landings were made in turbulence, flying qualities in pitch were only slightly degraded, whereas in roll they were severely degraded. 


\section{References}

1Berry, D.T., "Flying Qualities: A Costly Lapse in Flight-Control Design?" Astronaut. \& Aeronaut. Apr. 1982, pp. 54-57 and 35 .

2Berry D.T., Powers, B.G., Szalai, K.J., Wilson, R.J.: "In-flight Evaluation of Control System Pure Time Delays," AIAA 80-1626R, J. Aircraft, Apr. 1982, p. 318.

${ }^{3}$ Szalai, K.J., Felleman, P.G., Gera, J., and Glover, R.D., "Design and Test Experience With a Triply
Redundant Digital Fly-By-Wire Control System," AIAA Paper 76-1911, Aug. 1976.

${ }^{4}$ Cooper, G.E. and Harper, R.P., Jr., "The Use of Pilot Rating in the Evaluation of Aircraft Handling Qualities," NASA TN D-5153, 1969.

5"Military Specification: Flying Qualities of Piloted Airplanes," MIL-F-8785C, Nov. 1980.

6Meyers, T.T., Johnston, D.E., MCRuer, D., "Space Shuttle Flying Qualities and Flight Control system Assessment Study," NASA CR-170391, June 1982.

Table 1 Typical aircraft characteristics

\begin{tabular}{|c|c|c|c|}
\hline Gross weight, lb & 20,000 & $c_{m_{\delta_{e}}}$ & $-0.8 / \mathrm{rad}$ \\
\hline Wing area, $\mathrm{ft}^{2}$ & 375 & $c_{\ell_{\delta_{\alpha}}}$ & $0.049 / \mathrm{rad}$ \\
\hline $\begin{array}{l}b, f t \\
\bar{c}, f t\end{array}$ & $\begin{array}{l}35.67 \\
11.8\end{array}$ & $c_{\ell_{\delta_{r}}}$ & $0.01 / \mathrm{rad}$ \\
\hline $\bar{q}, 1 b / f t^{2}$ & 100 to 270 & $c_{\ell_{p}}$ & -0.35 \\
\hline$I_{x}, f t-1 b / \sec ^{2}$ & 11,280 & $C_{\ell_{r}}$ & 0.040 \\
\hline$I_{y}, f t-1 b / s^{2} c^{2}$ & 87,490 & $c_{\ell_{\beta}}$ & $-0.10 / \mathrm{rad}$ \\
\hline$I_{z}, f t-1 b / s e c^{2}$ & 94,000 & $c_{n_{\beta}}$ & $0.14 / \mathrm{rad}$ \\
\hline$c_{L_{\dot{\alpha}}}$ & $3.7 / \mathrm{rad}$ & $c_{n_{\delta}}$ & $-0.17 / \mathrm{rad}$ \\
\hline$c_{L_{\delta_{e}}}$ & $0.57 / \mathrm{rad}$ & $c_{n_{\delta_{a}}}$ & $0.006 / \mathrm{rad}$ \\
\hline$c_{m_{q}}$ & -6 & $c_{n_{r}}$ & -0.7 \\
\hline $\mathrm{c}_{\mathrm{m}_{\alpha}}$ & $-0.5 / \mathrm{rad}$ & $c_{n_{p}}$ & 0 \\
\hline$c_{m_{\dot{\alpha}}}$ & -0.42 & $c_{y_{\beta}}$ & $-1.0 / \mathrm{rad}$ \\
\hline
\end{tabular}


Table 2 Typical control system characteristics

\begin{tabular}{|c|c|}
\hline $\begin{array}{l}\text { Inherent time delay } \\
\text { (stick to surface), sec } \\
\text { (pitch and roll) }\end{array}$ & 0.130 \\
\hline \multirow{2}{*}{$\begin{array}{l}\text { Secondary actuator } \\
\text { (a11 axes) }\end{array}$} & $(126)^{2}$ \\
\hline & $s^{2}+176 s+(126)^{2}$ \\
\hline $\begin{array}{l}\text { Power actuators- } \\
\text { Horizontal tail } \\
\text { Ailerons } \\
\text { Rudder }\end{array}$ & $\begin{array}{l}12.5 /(s+12.5) \\
82 /(s+82) \\
44 /(s+44)\end{array}$ \\
\hline \multirow{2}{*}{$\begin{array}{l}\text { Stick shaping - } \\
\text { Pitch }\end{array}$} & \\
\hline & $\begin{aligned} \text { Uutput }= & 0.35 \times \text { input }+0.45 \\
& \times \text { input } \times \mid \text { input } \mid\end{aligned}$ \\
\hline Roll & Output $\begin{aligned}= & 0.13 \times \text { input } \\
& +0.116 \times \text { input } \times \mid \text { input }\end{aligned}$ \\
\hline $\begin{array}{l}\text { Prefilter - } \\
\text { Pitch }\end{array}$ & \\
\hline Pitch & $12 /(s+12)$ \\
\hline Ro11 & $10 /(s+10)$ \\
\hline $\mathrm{K}_{\mathrm{q}}$ & $0.5 \mathrm{deg} / \mathrm{deg} / \mathrm{sec}$ \\
\hline$K_{p}$ & 1.0 to $3.0 \mathrm{deg} / \mathrm{deg} / \mathrm{sec}$ \\
\hline$K_{L A}$ & $0.0435 \mathrm{deg} / \mathrm{deg} / \mathrm{sec}$ \\
\hline$k_{r}$ & $0.4 \mathrm{deg} / \mathrm{deg} / \mathrm{sec}$ \\
\hline$k_{p_{\delta_{r}}}$ & $0.005 \mathrm{deg} / \mathrm{deg} / \mathrm{sec}$ \\
\hline
\end{tabular}

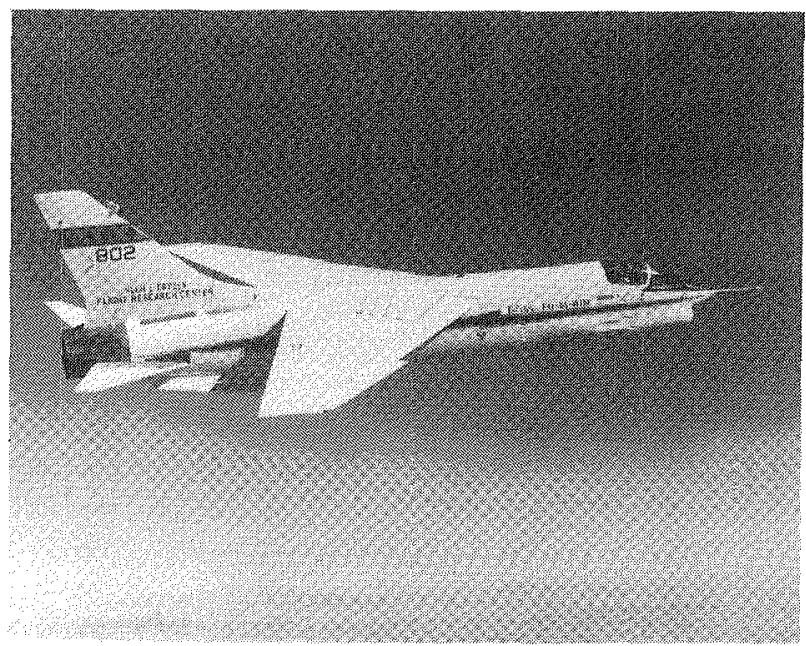

ECN 6981

Fig. 1 F-8 DFBW aireraft. 


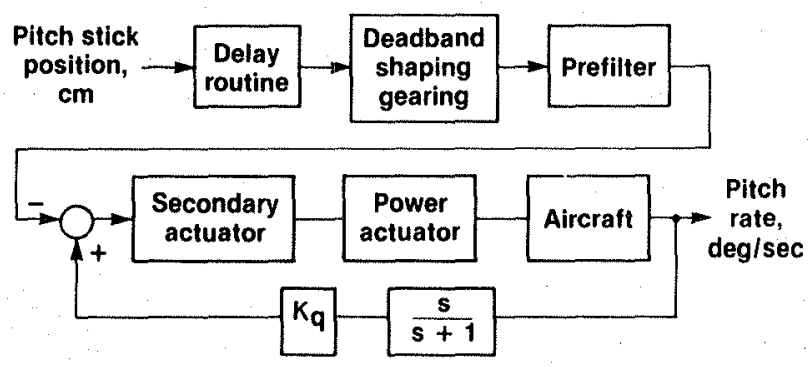

Fig. 2 Pitch SAS mode.

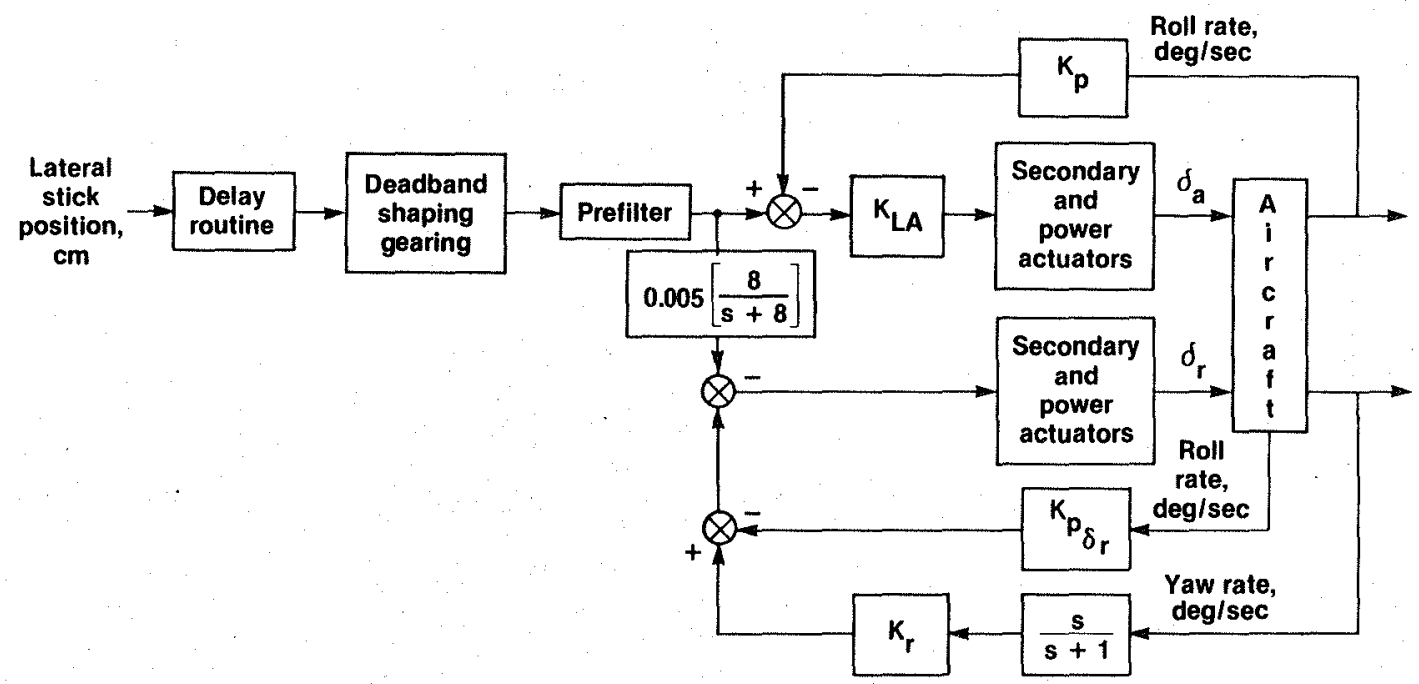

Fig. 3 Lateral-directional SAS.

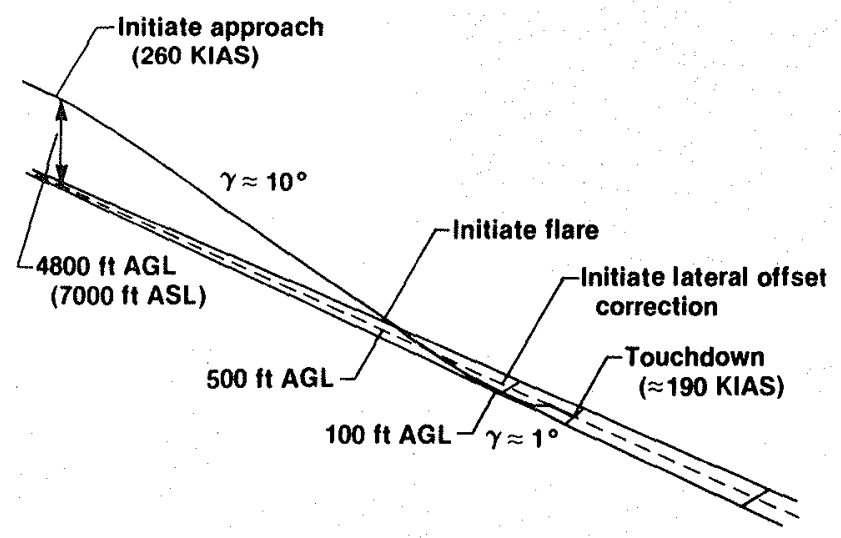

Fig. 4 Low-L/D landing approach pattern.

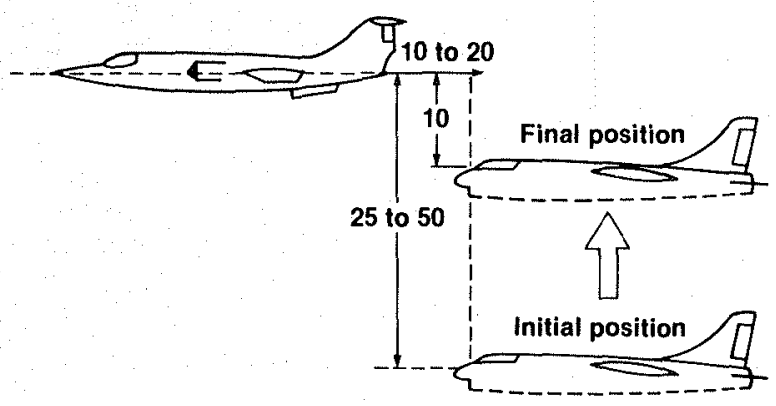

Fig. 5 Formation flying task. Dimensions are in feet. 


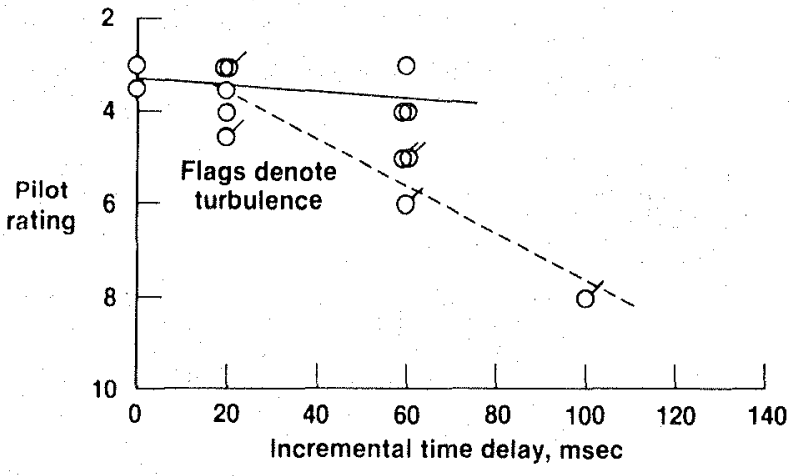

(a) Normal landings.

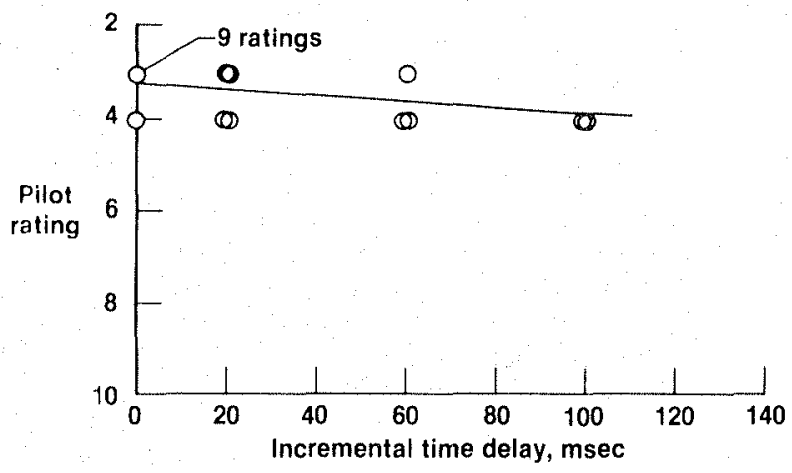

(b) Spot landings.

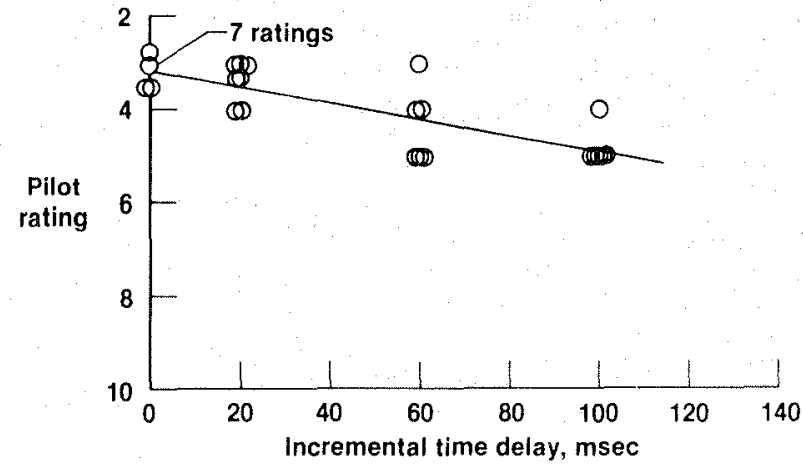

(c) Offset spot landings.

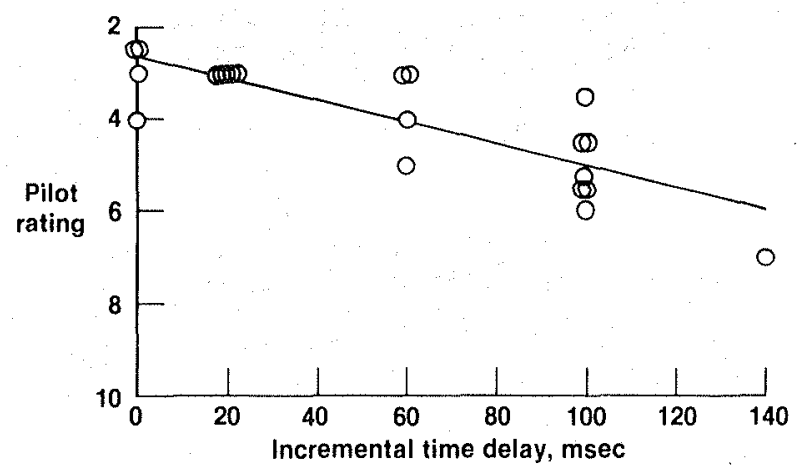

(d) Formation flying.

Fig. 6 Pilot ratings in roll axis. Coincident data points are shifted horizontally for clarity.
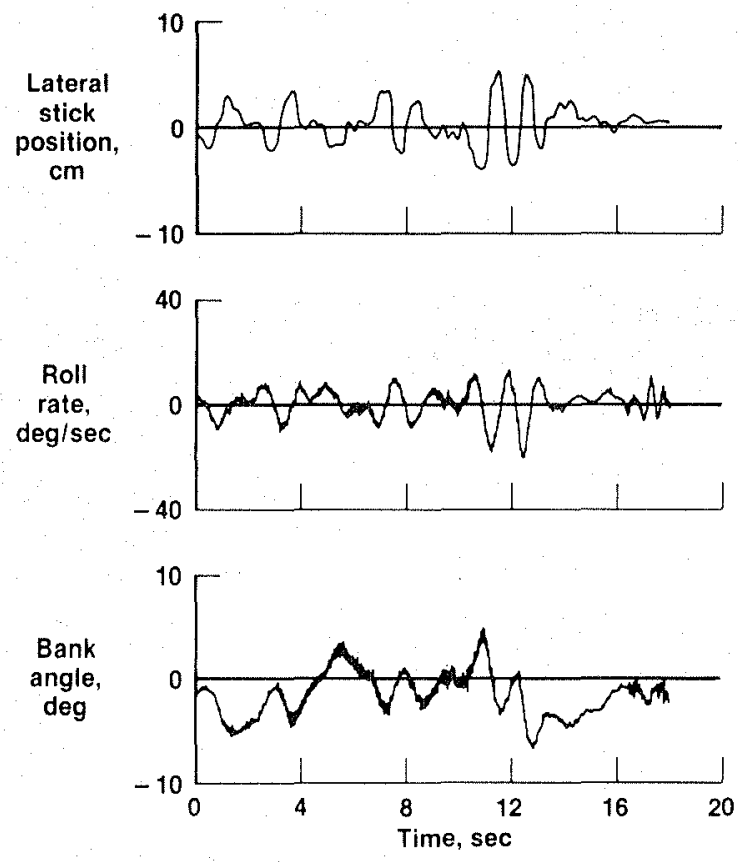

Fig. 7 Roll PIO during landing approach. Time dezay $=60 \mathrm{msec}$. 

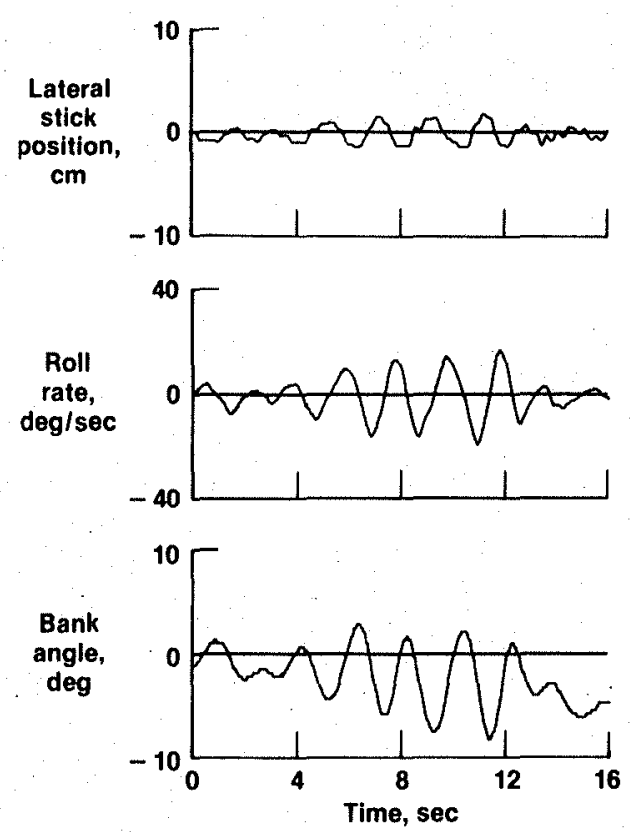

Fig. 8 Roll Pro during formation flying. Time delay $=140 \mathrm{mbec}$.

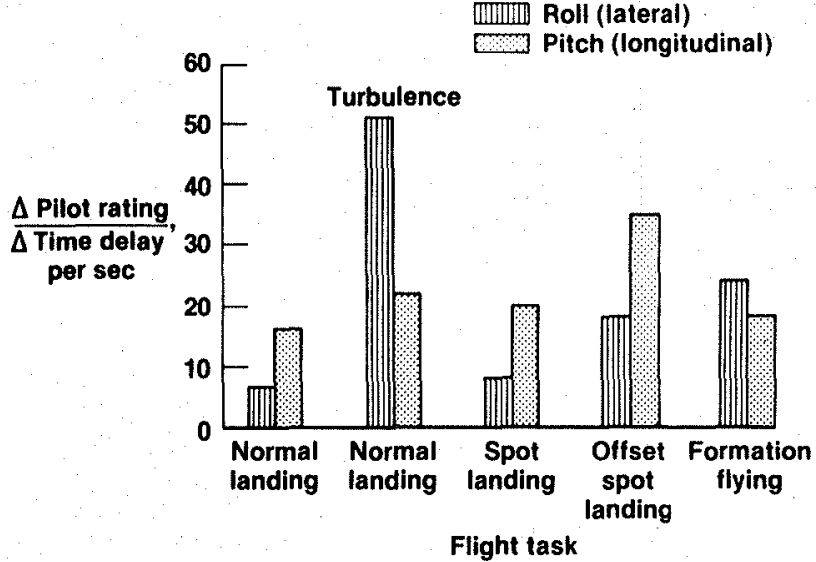

Fig. 10 Roll-pitch comparison.

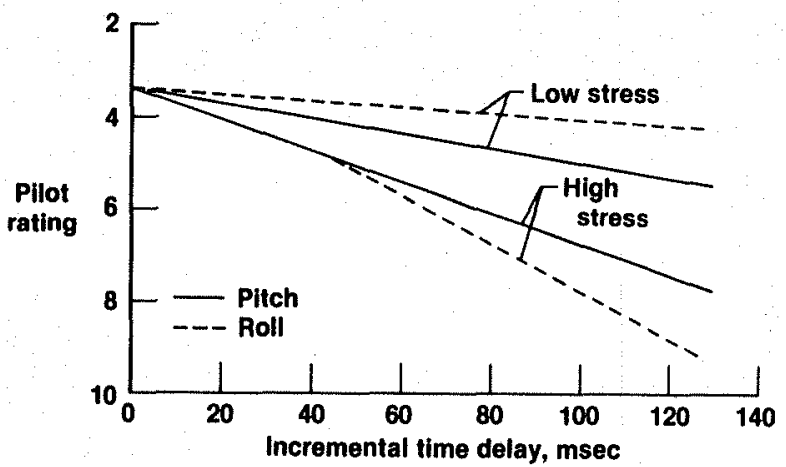

Fig. 11 Pilot rating summary.

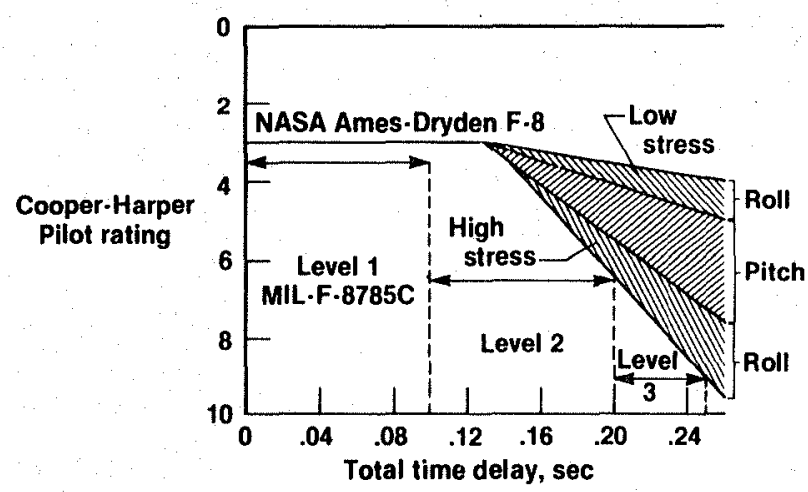

Fig. 12 Comparison of MIL-F-8785C time delay requirements with data from this study. 


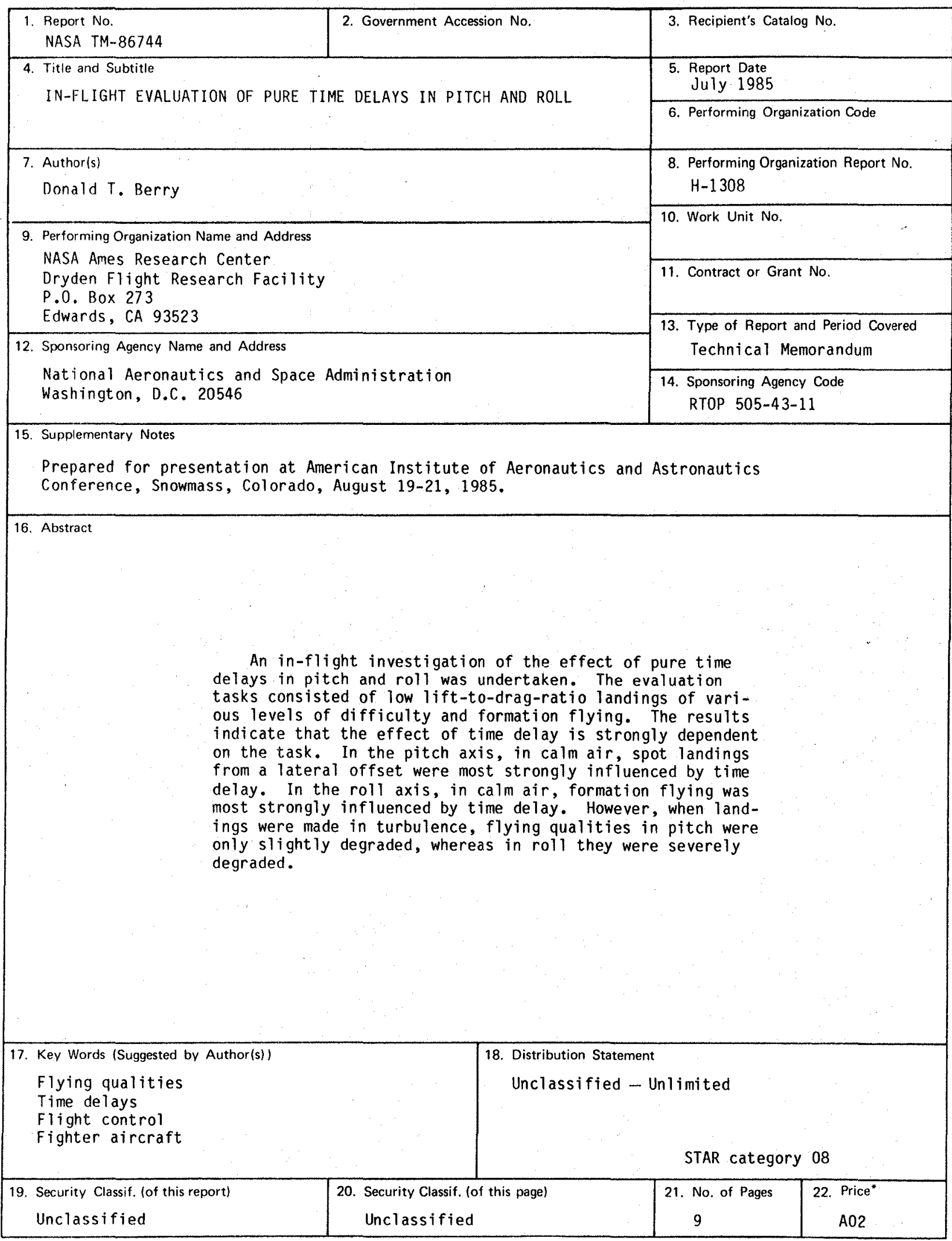

*For sale by the National Technical Information Service, Springfield, Virginia 22161. 


\section{End of Document}

